\title{
Ship Air-conditioning System Design Requirements and Energy-saving Measures
}

\author{
Qianjun Ye \\ School of Science, Wuhan Institute of Technology, Wuhan 430205, China \\ 352217510@qq.com
}

Keywords: Ship, air conditioning, design, energy-saving.

Abstract: Ships designed today are equipped with air conditioning units. The ship's central air conditioning design has its own particularity, and a reasonable design can significantly improve comfort and energy consumption. This paper analyzes the design parameters, design requirements and energy-saving measures, and puts forward the design suggestions for the ship air-conditioning system.

\section{Introduction}

In order to cope with the adverse effects brought by the harsh climate and seasonal changes in the navigation area, to ensure the comfort of the crew's working and living environment, and the important monitoring facilities in good working condition, the ships designed and built today are equipped with air-conditioning devices. The power consumption of marine air-conditioning equipment accounts for about $10 \%$ of the total power consumption of the ship. The design and management of a reasonable air-conditioning system can significantly reduce the energy consumption of air-conditioning.

\section{Design Parameters of Ship Air-conditioning}

According to the classification of the air conditioning system, the air conditioning of the ship is mainly used to maintain a good air quality in the cabin, and to provide a comfortable thermal environment for the ship personnel, which is a comfortable air conditioner. The thermal environment includes air temperature, air humidity, flow speed and cabin wall temperature. The freshness of the air, the clothing of the human body, the internal surface of the cabin wall and the temperature of the surface of the furniture all affect the thermal sensation of the human body. In order to ensure the air quality in the cabin, the ship air conditioning system must also ensure a certain amount of fresh air. The ship's air conditioning unit shall, within the specified outdoor operating conditions, ensure that the air in the cabin meets the requirements in Table 1. 
Table 1 Interior design parameters of ship air conditioning cabin

\begin{tabular}{|c|c|c|c|c|}
\hline Design condition & Temperature & Relative humidity/\% & Air freshness & Air velocity $/ \mathrm{m} / \mathrm{s}$ \\
\hline Summer condition & $24 \sim 28^{\circ} \mathrm{C}$ & $40 \sim 65$ & \multirow{2}{*}{$\begin{array}{l}\text { Less dust and harmful } \\
\text { gases, sufficient oxygen } \\
\text { content, fresh air } \\
\text { volume } \\
30 \sim 50 \mathrm{~m}^{3} / \mathrm{h} \cdot \text { person }\end{array}$} & $0.2 \sim 0.5$ \\
\hline Winter conditions & $18 \sim 22^{\circ} \mathrm{C}$ & $30 \sim 40$ & & $0.15 \sim 0.3$ \\
\hline
\end{tabular}

\section{Design Requirements of Ship Air-conditioning System}

\subsection{Temperature and relative humidity}

As far as past experience is concerned, the biggest factor affecting the comfort of the human body is the temperature. In general, the human's optimal somatosensory temperature is between $23^{\circ} \mathrm{C}$ and $24^{\circ} \mathrm{C}$, and the temperature change should not exceed $2^{\circ} \mathrm{C}$. In addition, considering the human's ability to sense the temperature, the temperature difference between the indoor temperature and the outdoor temperature of the air conditioner should not be too large, and should be controlled at about $8{ }^{\circ} \mathrm{C}$. In terms of humidity, just keep the indoor air at 50\% relative humidity. In addition, considering the impact of the air conditioning system on the overall energy consumption of the ship, the temperature range setting of the ship's air conditioner should not be too large, and it only needs to be kept in the comfortable temperature range of the human body. The reasonable temperature for indoor air conditioning should be between $23^{\circ} \mathrm{C}$ and $28^{\circ} \mathrm{C}$ in summer and $18^{\circ} \mathrm{C}$ to $20^{\circ} \mathrm{C}$ in winter.

\subsection{Air freshness}

In addition to adjusting the indoor temperature, the air conditioning system has another important role in regulating the freshness of the indoor air. The freshness of the indoor air is affected by the amount of air discharged and introduced by the air conditioning system. In order to ensure the breathing comfort of the person, the supply of fresh air is guaranteed to be about 2.5 cubic meters per hour of a person. Moreover, in order to simulate the outdoor environment, the air conditioning system also needs to form air flow indoors. According to different seasonal requirements, the air flow speed should be controlled between $0.15 \mathrm{~m} / \mathrm{s}$ and $0.20 \mathrm{~m} / \mathrm{s}$, and the maximum value should not exceed 0.35 $\mathrm{m} / \mathrm{s}$.

\section{Existing Energy-saving Measures for Ship Air-conditioning System}

The ship air conditioning device is an important device to ensure the safe navigation of the ship and the comfort of the crew. The power consumption of ocean-going air-conditioning systems of ships more than 10,000 tons is about $20 \%$ of the total capacity of the ship's power grid. It is the main energy-consuming device for ships. For the maritime industry, which accounts for more than $90 \%$ of the world's trade cargo volume, due to the high demand for fuel, in recent years, as international oil prices have continued to rise, ship operating costs have also increased. Therefore, how to achieve energy-saving and efficiency improvement of ship operations has become an important topic of increasing concern in the shipping industry. Ship air-conditioning system accounting for a large proportion of the total energy consumption of ships, how to improve its cooling efficiency and achieve energy consumption reduction has become an important research direction for ship energy conservation. 


\subsection{Adjust the opening of the thermal expansion valve}

Ocean-going vessels usually sail in the global waters. When the ship crosses the equator from the northern hemisphere to the southern hemisphere, or from the southern hemisphere to the northern hemisphere, the outdoor temperature difference may vary drastically within the range of 30 to $50{ }^{\circ} \mathrm{C}$, so the cooling load of the air conditioning system will vary over a wide range. Although the thermal expansion valve can automatically adjust the flow rate of the refrigerant according to the change of the external cooling load, so that the cooling capacity matches the cooling load, but the adjustment range is limited. When the ambient temperature rises, the pre-tightening force of the expansion valve spring originally set often cannot ensure that the refrigerant circulation amount is correspondingly increased, which will lower the evaporation pressure, reduce the refrigeration coefficient, and increase the energy consumption, so it is necessary to appropriately decrease the spring preload of the expansion valve; when the ambient temperature drops, the spring preload of the expansion valve should be increased appropriately. In the operation and management of ship air conditioners, engineers should reasonably adjust the spring preload of the expansion valve according to the change of the load to ensure proper opening, avoid energy consumption increase, and improve economy.

\subsection{Non-condensable gases in the regular discharge system}

The non-condensable gas in the system is mainly air, which usually accumulates in the condenser and the accumulator, which increases the power consumption of the compressor. Therefore, the engineer should periodically discharge the non-condensable gas to the atmosphere throughr the bleed valve on the accumulator and the condense to reduce power consumption.

\subsection{Regular oil discharge, avoiding a large amount of lubricating oil entering the heat exchanger}

Once the lubricating oil in the system enters the condenser and the evaporator, an oil film is formed on the surface of the system, which generates a considerable thermal resistance and reduces the heat transfer coefficient. Therefore, the compressor exhaust in the air conditioning system generally passes through the oil separator, and the majority of the lubricating oil is separated, and flows back to the compressor crankcase through an automatic float valve or a manual valve. During the management, the engineer should regularly check the automatic oil return of the oil separator. In the case of automatic oil return failure, the manual oil return should be used to prevent the lubricating oil from entering the heat exchanger in large quantities, so as to avoid the economical deterioration of the whole device.

\subsection{Regular descaling, increasing heat transfer coefficient and reducing energy consumption}

Studies have shown that when the condenser fouling thickness reaches $1.5 \mathrm{~mm}$, the average power consumption increases by $9.8 \%$. It can be seen that the regular removal and descaling of the condenser in the management of the turbine system is also an important energy-saving measure.

\section{New Energy-saving Measures for Ship Air-conditioning System}

Due to changes in the navigation area and day and night, the operating conditions and cooling load of the ship are also constantly changing. During the actual use of the ship's air conditioning unit, most of the time is under partial load, so the ship usually uses compressor intermittent operation or compression machine suction recirculation and other methods to achieve energy adjustment of the 
compressor. However, this method has the drawback that the cooling capacity and the cooling load cannot be completely matched, so that the cooling coefficient of the system is low during operation, especially at low load. In recent years, with the continuous development of frequency conversion technology and the sharp drop in the price of frequency conversion equipment, especially the mature application of frequency conversion technology in domestic refrigeration equipment, how to apply frequency conversion technology to marine air conditioning equipment to achieve substantial energy saving has become development trend of the current air conditioning research.

\subsection{Use frequency conversion technology to achieve energy regulation of the compressor}

Most of the ship's air-conditioner compressors are piston type and are not suitable for high-speed operation. Therefore, the maximum frequency of the inverter is limited to $60 \mathrm{~Hz}$ or less. In addition, the compressor lubrication method is pressure lubrication of the shaft gear pump. After lubricating the crankshaft and the bearing, the lubricating oil flows back to the crankcase through a hydraulic pressure regulating valve provided at the free end of the crankshaft. When the compressor speed decreases, the actual discharge pressure of the lubricating oil pump will decrease. The oil pressure regulating valve can be adjusted to maintain the lubrication pressure difference not less than $0.1 \mathrm{MPa}$, and the ship air conditioning unit is operated at $40 \%$ to 80 for most of the time under the rated load condition, and the efficiency of the whole device is higher at the speed of about $1000 \mathrm{r} / \mathrm{min}$, the speed of the compressor is preferably not less than $600 \mathrm{r} / \mathrm{min}$, and the frequency is above $20 \mathrm{~Hz}$.

\subsection{Using an electronic expansion valve to regulate refrigerant flow}

The traditional thermal expansion valve has a slow response, a long adjustment lag time, a small adjustment range, and a large flow pulsation, which cannot work normally beyond a certain flow range. The electronic expansion valve has good dynamic characteristics of variable load. It can be controlled by the microcomputer according to the preset regulation of the compressor. The pulse signal is used to control the direction of pulse motor and change the needle opening to precisely control the refrigerant flow. When the load of the air conditioning system of the ship changes greatly, the electronic expansion valve can quickly and directly measure the change of the superheat of the evaporator outlet and quickly transmit the signal to adjust accordingly, so that the evaporator outlet superheat is maintained in the range of $3-6^{\circ} \mathrm{C}$. Therefore, it is advisable to use an electronic expansion valve in the variable frequency speed control system.

\subsection{Use the frequency conversion speed regulation technology to adjust the air volume}

For ocean-going vessels of more than 10,000 tons, only the air-conditioning system's fan consumes about $8 \%$ of the ship's power grid capacity, and is a major energy consumer in various devices on board. When the compressor adopts frequency conversion speed regulation, if the speed of the air conditioner fan is not adjusted, when the compressor speed increases, the evaporation pressure will decrease, the energy efficiency ratio of the air conditioning system will decrease, and the economic efficiency of the whole system will deteriorate. At the same time, when the latitude is high, the room temperature will be low, the air volume will be too large, the back pressure of the air-conditioning fan will increase, the fan will surge, and the airflow noise will increase. Therefore, research on fan air volume regulation is another important way to save energy in ship air conditioning. At present, there are two main air volume adjustment methods for the fixed-flow single-duct system of fixed-speed fans commonly used in marine air-conditioning systems. One is the air venting method. When the air volume of the air duct is large and the static pressure of the air duct exceeds a certain 
value, the excess treated air is discharged to the return air corridor between the cabins through the discharge port. This method consumes a large amount of energy. The second is the fan air outlet damper throttling method. When the external load is small, adjust the throttle valve in the air distribution box of the fan air outlet to adjust the air pressure. However, this throttling adjustment method will make the wind channel characteristic curve steeper, and the fan will surge, and this method consumes a lot of energy. The use of fan frequency control is an effective way to solve the problem of large energy consumption adjustment.

\section{Conclusions}

In the harsh sea conditions and changing weather conditions, modern ship air-conditioning devices should not only achieve air conditioning and comfort functions, but also have high-precision, energy-saving and high-efficiency technical features and excellent performance. In addition to the traditional energy-saving measures, the compressor variable frequency speed regulation, the fan air volume frequency conversion adjustment, the use of electronic expansion valve for the refrigeration device flow energy adjustment, will be the main technical measures for the realization of electronic control and energy saving of the ship air conditioning system.

\section{References}

[1] LOU Jianwei. Talking about the Energy Saving Work of Ships[J]. China Water Transport, 2012, 12(8):1-2.

[2]LI Min, LI Zhan. Design and Research of Air-Conditioning System of Heat Recovery Ship with Cool Storage Device[J]. China Ship Repair, 2008, 21(3):20-23.

[3] ZHANG Jianhua, Yan Ankang, Han Houde. Energy Analysis and Energy Saving Measures for Ship Central Air Conditioning System[J]. Shanghai Shipbuilding, 2011(1):59-61.

[4] HE Changwei. Research on energy-saving technology of marine air-conditioning units [J]. HVAC, 2005, (12):118-119. 